\title{
Una variante rioplatense del indianismo hispanoamericano: el Tabaré de Juan Zorrilla de San Martín
}

\author{
Roberto CAmpa MAdA*
}

Resumen:

Este ensayo postula la especificidad de Tabaré (1888), de Juan Zorrilla de San Martín, en el contexto del indianismo hispanoamericano. Frente al "indio" estilizado y heroico del romanticismo de otras regiones, el Cono Sur traza la figura de un salvaje pendenciero y reacio a la civilización. En la encrucijada de estas dos tradiciones surge Tabaré, que recoge tópicos del romanticismo rioplatense (como el de los malones y el de la cautiva, en el marco de la dicotomía civilización/barbarie) para contribuir a la construcción ideológica de una nación uruguaya que busca legitimar sus raíces en un imaginario pasado indígena de tintes heroicos.

Palabras clave:

Tabaré, Juan Zorrilla de San Martín, indianismo, romanticismo rioplatense, nacionalismo uruguayo.

\section{Introducción}

El XIX constituye para Hispanoamérica el siglo de la fundación y delineamiento de los imaginarios e idearios nacionales, que encontraron en el periodismo y la literatura vehículos idóneos de

* Universidad de Sonora. 
difusión. En esa búsqueda de elementos propios que catalizaran la separación y diferenciación definitivas con la metrópoli, se destacaron los dos ejes temáticos sobre los cuales giraría una parte importante de las obras literarias producidas en las nuevas naciones: el indígena y la naturaleza americanos, que protagonizaron -sobre todo el primero- lo que un amplio sector de la crítica ha catalogado como literatura indianista. ${ }^{1}$

En su ya clásico estudio La novela indianista en Hispanoamérica, Concha Meléndez rastreó con paciencia, en la década de los treinta, una numerosa nómina de obras hispanoamericanas adscritas al romanticismo literario, protagonizadas por personajes autóctonos de América. Desde entonces se ha vuelto convención considerar indianistas las obras en las que el personaje indígena se presenta, al estilo romántico, exotizado y estilizado; e indigenistas, aquellas en que el tema indígena empezó a recibir un tratamiento más sociológico, estilo asociado con las corrientes realistas y que se impuso a lo largo del siglo XX. ${ }^{2}$

${ }^{1}$ A esta nomenclatura se adhieren críticos de distintas épocas y tendencias, como Luis Alberto Sánchez, Aída Cometta, Robert Bazin, Antonio Sacoto, César Rodríguez Chicharro, Tomás G. Escajadillo, Julio Rodríguez-Luis, etc. El mismo Antonio Cornejo Polar se refiere, aunque con reticencia, a esta denominación: "lo que tal vez ayuda a comprender mejor el significado del término indianismo es su incorporación al sistema estético e ideológico del romanticismo" (36). El crítico peruano prefiere llamarlo "indigenismo romántico" y en el caso de su país verlo como una etapa "de un largo y accidentado proceso que recorre, y en cierto modo vertebra, el curso de la literatura peruana" (37), y puntualiza que, para el caso de Perú, "en el plano de la productividad textual nuestro indigenismo de este tipo fue excepcionalmente pobre $-y$ se estaría tentado de declararlo inexistente" (37).

${ }^{2} \mathrm{Al}$ estudiar, en 1959, las novelas mexicanas indigenistas, César Rodríguez Chicharro las divide en indianistas, indigenistas y novelas de recreación antropológica. Tomás G. Escajadillo, por su parte, al trazar la línea evolutiva del tema indígena en el ámbito peruano, distingue cuatro modalidades: indianismo modernista, indianismo romántico-realista-idealista, indigenismo ortodoxo y neo-indigenismo. Para Julio Rodríguez-Ruiz, "La importancia del indio como objeto cultural, demostrada con creces por una tradición indianista estrechamente ligada con la búsqueda romántica de lo autóctono americano (Tabaré, 
Porque no era el indígena conciudadano y contemporáneo, que sobrevivía en la sombra, al margen de los proyectos nacionales, el que sirvió de inspiración al indianismo, sino su lejano antepasado visto tras una lente idealizante. El indianismo configuró un personaje artificial, concebido según los parámetros del héroe romántico de rol sentimental y cívico. Como explica Aída Cometta en El indio en la poesía de América española:

Pero el indio, ¿qué papel desempeña en este periodo? Es un simple decorado, un elemento exótico que se explota para dar "color local" a la nueva literatura. Es evocación artística, su presente nada interesa a los románticos, pero en su pasado encuentran temas para sus cantos. Lloran ese pasado glorioso, evocan los imperios poderosos y se lamentan, en romances y elegías, de la desgraciada suerte que le cupo a la raza vencida (155).

Son los Guatemozines, los Jicotencatl, los Enriquillos, las Anacaonas, quienes serán rescatados desde las crónicas de la conquista y desde sus nichos legendarios para protagonizar los roles patéticos requeridos en los dramas románticos. Los héroes autóctonos vuelven a cobrar vida travestidos según los modelos importados de los románticos europeos, porque como reconoce Luis Alberto Sánchez: "el indianismo literario nos vino de afuera, de una curiosidad egotista y europea y que, por imitación, la adoptamos nosotros haciendo nuestro lo ajeno que, sin embargo, era de raíz absolutamente nuestra" (23) y por lo tanto no queda sino darse cuenta "de que el material de tales obras es europeo, aunque los protagonistas y la topografía se vistan de arreos indios" (11).

El romanticismo rioplatense, por su parte, difundió una imagen diametralmente opuesta. Frente al indio idealizado y estilizado del

Cumandá, Enriquillo), ayuda al mismo tiempo a subrayar la preeminencia del indigenismo en el panorama de la literatura de intención social de nuestro continente" (Rodríguez-Luis 8). 
indianismo de otras regiones, ${ }^{3}$ el Cono Sur traza la figura de un salvaje degenerado y reacio a la civilización. Es en la encrucijada de estas dos tradiciones que surge el Tabaré (1888) de Juan Zorrilla de San Martín que, como intentaré mostrar, constituye una versión diferente del indianismo, una versión que recoge tópicos (como el de los malones y el de la cautiva, así como la dicotomía civilización-barbarie) del romanticismo rioplatense para contribuir a la construcción y consolidación de un nacionalismo uruguayo que busca sus raíces en un imaginario pasado indígena de tintes heroicos.

\section{El antiindianismo en la literatura rioplatense}

Cuando Concha Meléndez utilizó el adjetivo indianista para referirse a un gran número de estas obras con temática indígena, lo definió en términos afectivos. En ellas los indios y sus tradiciones debían estar presentados con "simpatía". Y aunque reconocía una gran variedad de matices en dichas obras y autores, dice que "todos ellos, empero, simpatizan con el indio, que describen embellecido o estilizado, en contraste con aquella literatura antiindianista -los poemas argentinos Santos Vega, de Ascasubi, y Martín Fierro, de Hernández, por ejemplo- de indios holgazanes, crueles y abyectos" (14).

Es significativo que los dos ejemplos que Meléndez da de literatura "antiindianista" provengan del ámbito argentino. Y es que, en

\footnotetext{
${ }^{3}$ Algunos ejemplos de novelas indianistas en Hispanoamérica, y que son descritas en el citado estudio de Concha Meléndez, son: el anónimo Jicoténcatl (1826); Netzula (1832) de J. M. L. (¿José María Lafragua o José María Lacunza?); Matanzas y Yumuri (1837) de Ramón de Palma y Romay; Guatimozin, último emperador de México (1846) y El cacique de Turmequé, leyenda americana (1860), de Gertrudis Gómez de Avellaneda; Los mártires del Anábuac (1870) de Eligio Ancona; Anaida (1860) e Iguacaya (1872) de José Ramón Yépez; Nezahualpilli (1875) de Juan Luis Tercero; Cumandá o Un drama entre salvajes (1877) de Juan León de Mera; Azcaxóchiotl o la flecha de oro (1878) de J. R. Hernández; Enriquillo (1879) de Manuel de Jesús Galván; Amor y suplicio (1873) y Doña Marina (1883), de Ireneo Paz; La bija de Tutul-Xiu de Eulogio Palma y Palma; Huincahual (1888) de Alberto del Solar; entre otras.
} 
verdad, resulta problemático hablar de literatura indianista, al menos en el sentido tradicional del término, en el romanticismo argentino, donde los indígenas tienen siempre una participación secundaria y, en general, aparecen trazados de forma negativa, como el componente salvaje del modelo dicotómico civilización/barbarie.

El cono sur generó sus propios mitos que sustentan una producción literaria que intentaba recrear la experiencia de la conquista en esa zona. El folclore rioplatense reflejó las condiciones hostiles del encuentro entre indígenas y colonizadores, y abundó en historias de cautivas, víctimas de los "malones", o ataques sorpresivos de los indios. La más importante es la leyenda de Lucía Miranda, que inspiró una variedad de obras ensayísticas, dramáticas, narrativas y poéticas después de que Ruy Díaz la incluyera en su Argentina, en 1612. ${ }^{4}$ Se trata de una leyenda de tintes hagiográficos, en la que los mártires son un soldado español, Sebastián Hurtado, y su esposa, Lucía Miranda, la cual es raptada en un malón por Siripo, un cacique timbú. Cuando Hurtado va a rescatarla, ambos mueren por órdenes del cacique: ella en una hoguera y él asaeteado por los indios en el tronco del árbol en el cual está atado. La alusión a los santos de la tradición martiriológica es evidente: se trata de una reproducción de los martirios de San Sebastián ${ }^{5}$ y Santa Lucía en escenario americano. Ya en el siglo XIX se escriben, de manera simultánea e independiente, dos versiones noveladas de Lucía Miranda (la de Rosa Guerra y la de Eduarda Mansilla de García, publicadas ambas en 1860) que siguen de cerca el modelo de la Atala de Chateaubriand, introduciendo un fuerte componente religioso (en la versión de Guerra, Mangoré agonizante pide ser bautizado) y una serie de descripciones exotistas de los indios y la naturaleza.

${ }^{4}$ Estos eventos se narran en el capítulo VII del libro primero en La Argentina de Ruy Díaz de Guzmán.

${ }^{5}$ En un artículo publicado en 1919 en la Revista de la Universidad de Córdoba, Martiniano Leguizamón demuestra la falta de historicidad del episodio y concluye que la leyenda es invención de Ruy Díaz, "sugerida por la historia del martirio de San Sebastián, que murió asaeteado” (cit. en Meléndez 86). 
Pero como esta, hubo muchas otras historias de cautivas, reales o imaginadas, que según Medina Vidal fueron "consecuencia emotiva de esa lucha entre conquistadores y conquistados" (4). En su estudio titulado El tópico de "La Cautiva" en la literatura rioplatense, Medina Vidal señala que "esta presencia de Lucía Miranda se integró en un fondo común legendario, que alimentó la imaginación de nuestros románticos. A veces venían sus figuras de las viejas crónicas, otras de la tradición oral, otras de pequeños dramas o narraciones” (6). En todas ellas está perfectamente delineado el irreductible antagonismo de las razas en pugna, su incompatibilidad cultural, la violencia de su encuentro, marcas que se conservarían hasta el siglo XIX, en el que el romanticismo llegó al cono sur representado en la llamada generación del 37, que retomaría este tópico para integrarlo en el modelo basado en la oposición civilización-barbarie que definió su búsqueda estética y su ideología política.

Las tesis sobre el indio que prevalecieron en la generación romántica argentina eran más cercanas a las estadounidenses que a las del resto de Hispanoamérica, como la experiencia histórica en los márgenes del Plata había sido también más similar a la del país anglosajón. ${ }^{6}$ Esto se reflejó en una literatura antitética a la corriente indianista que se desarrolló en otros países. Los textos fundamentales de las diversas etapas del romanticismo argentino reprodujeron y reforzaron los mismos esquemas. Desde el poema de La Cautiva, de Echeverría, hasta el Martín Fierro, de Hernández, pasando por el Santos Vega de Hilario Ascasubi, se nos muestra a un indio salvaje, pendenciero, dado a las orgías y al alcohol; un ladrón y asesino

\footnotetext{
${ }^{6}$ Como nota Verdesio, en buena parte del territorio argentino, como en Uruguay, "la colonización estuvo basada en estrategias que son típicas de lo que algunos investigadores han llamado settler colonialism o colonialismo de colonos o pioneros . . . un tipo de colonialismo que no se basa en la obtención de una plusvalía importante a partir de la explotación del trabajo esclavo o semiesclavo de vastas masas de indígenas (tipo de explotación que predominó en áreas de temprana colonización, en los Andes y Mesoamérica), sino en el desplazamiento o en el exterminio (si el desplazamiento falla) de los habitantes nativos del territorio" (90).
} 
sanguinario que representaba un peligro constante para las poblaciones y una amenaza por erradicar; en suma, una figura que no tiene nada que ver con el indio idealizado y heroico de la corriente indianista. Este último tiene uno de sus principales precursores e influencias en La Araucana de Ercilla. Domingo Faustino Sarmiento se burla de estos tempranos modelos:

Los araucanos eran más indómitos, lo que quiere decir, animales más reacios, menos aptos para la civilización, y resistieron ferozmente, porque feroces eran, la conquista y asimilación europeas. Desgraciadamente, los literatos de entonces eran más poéticos que los de ahora, y a trueque de hacer un poema épico, Ercilla hizo del cacique Caupolicán un Agamenón, de Lautaro un Ajax, de Rengo un Aquiles . . . para nosotros Colocolo, Lautaro y Caupolicán, no obstante los ropajes nobles y civilizados de que los revistiera Ercilla, no son más que unos indios asquerosos, a quienes habríamos hecho colgar ahora, si reapareciesen en una guerra de los araucanos contra Chile, que nada tiene que ver con esa canalla (cit. en Sacoto 46)

Persiste en esta generación la idea de la inferioridad del llamado "indio" y su supuesto salvajismo inherente, su incapacidad para incorporarse a los nuevos modelos de nación. Estas preconcepciones y estereotipos son reproducidos y reforzados en gran parte de la obra ensayística y ficcional de este periodo.

\section{El indianismo uruguayo y Tabaré}

A pesar de que normalmente se clasifica como la última obra del indianismo hispanoamericano ${ }^{7}$ (se publicó en 1888, un año antes

\footnotetext{
${ }^{7}$ Robert Bazin la consideró el canto del cisne de Zorrilla de San Martín y del indianismo americano.
} 
de la aparición de Aves sin nido de Clorinda Matto de Turner, que se dice marca el paso hacia una literatura indigenista, de denuncia social sobre las condiciones de explotación sistemática que padecen los pueblos indígenas), Tabaré no responde del todo a los parámetros de este movimiento donde el elemento indígena, aunque exótico y europeizado, constituye el elemento central a partir del cual se interpreta el universo de la obra y es, por tanto, juzgado favorablemente en relación con el conquistador español. En el caso del poema de Zorrilla de San Martín, pesaron en tal manera el paradigma de oposición binaria civilización-barbarie y el sentimiento hispanófilo, que lo que se proyectaba como una epopeya en homenaje a una desaparecida raza heroica termina siendo una apología del exterminio.

Más cerca del indianismo literario que se practicó en otras regiones están la novela Abayubá (1873), de Florencio Escardó, las obras líricas de Adolfo Berro y Melchor Pacheco y Obes, y la obra dramática de Pedro Bermúdez. Los indianistas uruguayos no contaban, entonces, como sus contrapartes de otras zonas, ${ }^{8}$ con una amplia variedad de fuentes de donde nutrir una literatura indianista robusta en su país, lo que explica que esta haya consistido nada más que de alguna que otra aislada obra narrativa, dramática y lírica.

Estas obras, aunque escasas, reflejan la simpatía hacia el indígena que caracterizó a la llamada literatura indianista. El romance de Adolfo Berro "Yandubayú y Liropeya" 9 (1840) muestra una pareja

${ }^{8}$ Zonas como la mesoamericana, la andina o la caribeña, cuyas experiencias de conquista fueron profusamente documentadas.

${ }^{9}$ El episodio heroico de los amores de Yandubayú y Lirompeya, aparece por primera vez narrado a finales del siglo XVI por el arcediano Martín del Barco Centenera en su crónica versificada La Argentina y conquista del Río de la Plata, una de las escasas fuentes en que abrevó casi toda la obra indianista rioplatense. Esto sugiere Zum Felde al referirse al carácter inventivo de Tabaré: "Cierto es que la carencia misma de tradición épica, en lo que se refiere a ese período de la historia uruguaya, obligaba al poeta a inventar su personaje y su argumento. Del pasado indígena y de las luchas del aborigen con el conquistador, ninguna leyenda quedaba en la tradición popular ni en las páginas de los cronistas que no fuese de 
ejemplar de indígenas cuyo valor y heroísmo contrastan con la bajeza y la cobardía del soldado español, a quien el poeta se refiere como "el sangriento Carvallo". El conquistador mata a traición al "cacique preclaro", una vez que éste lo ha liberado (a petición de Liropeya) después de someterlo en lucha cuerpo a cuerpo. Este retrato de Carvallo es por cierto mucho más crítico que el de la fuente original (de Centenera), que en ningún momento destaca la cobardía del acto de traición y, por el contrario, muestra una profunda empatía hacia el soldado, quien recibe toda la compasión de la voz lírica, que además lo justifica y demanda también la simpatía del lector:

Lo que el triste mancebo sentiría

contemple cada cual de amor herido.

Estaba muy suspenso qué haría, y cien veces matarse allí ha querido (canto XII).

La pieza dramática de Bermúdez, titulada El Charrúa, sigue también la tónica indianista de Berro al poner la leyenda de Liropeya (Lirompeya) en el contexto de la lucha patriótica del charrúa ante el invasor español. Los indígenas, como ejemplo cívico, están en primer plano y la obra tiene un marcado sentido antiespañol. Como apunta Fabio Wasserman, así haya sido por cuestiones partidistas, "Bermúdez se propuso desarticular las representaciones negativas sobre los charrúas, reivindicando su modo de existencia" (128). ${ }^{10}$

Tabaré, en cambio, como ya hemos esbozado, sigue un camino muy distinto al de sus antecesores uruguayos. No se le puede

carácter puramente militar, exceptuando el episodio de Liropeya, que narra el Arcediano Barco Centenera en su pesado cronicón en verso, y que ya había dado tema al breve ensayo poemático de Adolfo Berro, en 1838" (xv).

10 “'Tomando distancia de los estereotipos corrientes, Bermúdez propone una estilización de los charrúas a quienes dota de una fisonomía atractiva y les atribuye costumbres y hábitos dignos de encomio como su propensión a la igualdad, valentía, lealtad, sentido de la independencia. Además muestra que se regían por leyes, procurando desmentir así a quienes los imaginan sumidos en la barbarie" (Wasserman 126). 
catalogar como una obra plenamente indianista, aunque tenga ciertos rasgos de esta estética, puesto que sigue al mismo tiempo la lógica de la ideología antiindianista, que ya hemos descrito. A la hora de armar el cuadro de estimaciones y denigraciones, en el caso de Zorrilla de San Martín la balanza se inclina notoriamente hacia el lado contrario que la de sus compatriotas Berro o Bermúdez; sus indios se parecen sospechosamente a los de Echeverría, Ascasubi y Hernández. Fuera de Tabaré (un alma española atrapada en un cuerpo de indio) los demás charrúas en el poema tienen un comportamiento acorde al modelo del romanticismo argentino. Generalmente aparecen en masa salvaje y animalizada:

Las tribus embriagadas

aullaban a lo lejos. . (607-08) $)^{11}$

y aun cuando se individualiza un personaje, resaltan los rasgos ya mencionados:

Tras la salvaje orgía

vendrá el cacique ebrio;

vendrá a buscar a su cautiva blanca ... (611-13).

El pueblo charrúa se presenta desprovisto de rasgos de humanidad. ${ }^{12} \mathrm{El}$ poeta traza constantemente paralelismos entre el indio y la fauna salvaje:

Cruza el salvaje errante

la soledad de la llanura inmensa,

${ }^{11}$ Los números entre paréntesis corresponden al número de verso o del rango de versos correspondientes en la edición de 1984 a cargo de Antonio Seluja.

${ }^{12}$ Esta asimilación entre los charrúas y las fieras ya ha sido notada por Annie Houot. Para la investigadora francesa: "El Charrúa sería de alguna manera el representante de una sub-humanidad, de ahí la expresión compuesta, hombre-charrúa que definiría un tipo humano no totalmente realizado". La autora enfatiza además que "en todas esas imágenes el comparante animal es siempre portador de valores negativos" (273). 
y el amarillo tigre, como él hosco como él fiero y desnudo, la atraviesa (245-48).

A lo largo del poema, la voz poética va semantizando la animalidad del charrúa, para reforzar la dicotomía que sostiene toda la obra: indio-salvajismo contra español-civilización. En la segunda sección del canto primero del libro segundo, después de describir las edificaciones del poblado español, agrega connotaciones animalescas a la habitación del indio:

En una tierra, madriguera hermosa

del indio más bizarro

de los que aullaron y aguzaron flechas

en el salvaje mundo americano.

El indio aúlla (773), ruge (779), brama (3469), jadea (3092), emite alaridos, feroces y rabiosos (785), además, se expresa "con ronca gritería" (3464), mientras que todos los actos de habla son reservados al español. Dentro de esta animalización para denotar lo salvaje, la comparación más abundante es la del indio con el tigre, que se convirtió en tópico en el romanticismo rioplatense. Está en Ascasubi al describir el malón, en el canto XIII de su Santos Vega:

y así fuerzan y degüellan niños, ancianos y mozos; pues como tigres rabiosos en ferocidad descuellan; en La cautiva de Echeverría:

Y tu vida, más preciosa que la luz del sol hermosa, sacar de las fieras manos de estos tigres inhumanos (canto 3).

y está también en el Martín Fierro, sólo por mencionar tres ejemplos correspondientes a obras fundamentales de dicho periodo:

Se debe ser precavido cuando el indio se agazape: 
en esa postura el tape vale por cuatro o por cinco: como el tigre es para el brinco y fácil que a uno lo atrape (IX).

Resulta significativo el cambio de paradigma respecto a las obras indianistas que se producían en otras regiones, donde la visión era la contraria: eran los españoles los "bárbaros", los "tigres”, que destruían una avanzada civilización. Tenemos un ejemplo en Guatimoc (1827), del colombiano José Fernández Madrid, quien repite el símil del tigre con la machacona insistencia de los románticos argentinos, aunque invirtiendo la ecuación:

Ven, pues a libertarnos con la muerte del suplicio horroroso que nos causa el escucharte, tigre carnicero. ¡Sí, tigres! ¡Hijo mío, esposa cara! ¿Dónde estáis?, ¿dónde estáis? ¡Acaso, dioses, ahora se hallarán entre las garras de los tigres! (cit. en Meléndez 74).

Pero si por un lado, Zorrilla de San Martín sigue el camino opuesto de sus predecesores, los indianistas uruguayos, por el otro tampoco se ajusta del todo al modelo de los románticos argentinos, cuyo pensamiento gira, según Antonio Sacoto, alrededor de dos centros: 1) un odio profundo hacia España; y 2) la erradicación del elemento indígena para sustituirlo con emigrantes europeos (34). Aunque comparte el fervor patriótico y nacionalista de estos, la obra de Zorrilla de San Martín está fundamentada en una cosmovisión hispanófila y católica. Estos dos elementos proveen el andamiaje que estructura la lógica de casi toda su obra. Tabaré, como dice Anderson Imbert, es un poema "concebido teológicamente" (19).

Esa concepción teológica se trasluce incluso en la idea particular que tiene Zorrilla de San Martín respecto a lo que es una epopeya, la cual aparece expresada en el glosario de Tabaré: 
¡La epopeya! Oigo clamar al tratadista de retórica y poética. ¡La epopeya, con un salvaje obscuro por protagonista, y con un caserío y una selva por teatro! ¡La epopeya en verso asonado, y sin octavas reales! . . ¿Y lo maravilloso?, se me dice. Precisamente, lo maravilloso en la epopeya es la desaparición de la voluntad humana como agente de la acción, a fin de que esta sea movida por una fuerza superior. Y cuando la criatura desaparece, no hay término medio: tiene que aparecer el Creador. La encarnación de sus leyes misteriosas en los seres humanos se llama creación épica (324).

Es bajo este registro que debe leerse Tabaré para comprender su armazón conceptual. Todo forma parte de un plan divino, incomprensible para los hombres, que no alcanzan a entender el misterio de la caída de la raza charrúa, pero que el poeta intuye se da en función a alguna nebulosa rebelión de tintes miltonianos ante el creador:

Nacida para el bien, el mal la rinde;

Destinada a la paz, vive en la guerra...

Hojas perdidas de su tronco enfermo,

El remolino las arrastra enfermas (277-80)

En este orden divino, España aparece como el instrumento escogido por Dios, con base en sus méritos, para llevar salvación al continente virgen, en una atmósfera de lucha apocalíptica:

Sólo España ¿quién más? sólo ella pudo,

Con pasmo temerario.

Luchar con lo fatal desconocido;

Despertar el abismo y provocarlo;

Llegarse a herir el lomo del desierto

Dormido en el regazo

De la infinita soledad su madre,

Y en él cavar el pabellón cristiano,

Y resistir la convulsión suprema

Del monstruo aquél al revolverse airado, 
Sin que el pavor le acongojara el alma,

Ni el resistir le desarmara el brazo (815-25).

Si en el indianismo se idealiza la figura del indio, despojándola de todos sus posibles defectos para revestirla de perfección y virtud, en Tabaré, por el contrario, Zorrilla de San Martín transfiere ese elemento de idealización a España y su misión en América:

España va, la cruz de su bandera,

Su incomparable hidalgo;

La noble raza madre, en cuyo pecho

Si un mundo se estrelló, se hizo pedazos (803-06).

Esta revalorización de España y lo español responde a una reacción que por las últimas décadas del siglo XIX algunos escritores -el ecuatoriano Juan Montalvo y el mexicano Ireneo Paz, entre otrosopusieron ante la corriente de antiespañolismo que había predominado en la literatura de las seis primeras décadas, más acendrado entre los intelectuales del romanticismo argentino, pero que también había prevalecido en la temprana obra indianista, influida por las obras de Marmontel y de Voltaire. ${ }^{13} \mathrm{Si}$ antes los conquistadores aparecían como ambiciosos, crueles y codiciosos, y Eligio Ancona, en su Mártires del Anábuac, hacía a Cortés confesar: "Los españoles padecemos una enfermedad del corazón que solo se cura con ese metal" (cit. en Meléndez 96); en Tabaré, por el contrario, Zorrilla construye un capitán Don Gonzalo de Orgaz que funciona como un modelo de virtud e hidalguía: "Era noble y valiente, noble y bueno, / Bueno y celoso de su estirpe hidalga" (1097-98).

No se trata ya de obra de invasores, sino de elegidos del misterio para llevar a cabo algún noble fin, quizás llevar la civilización a las tierras salvajes:

${ }^{13}$ Estos censuraban la conquista y atribuían al fanatismo religioso de los invasores las crueldades cometidas, como parte de la leyenda negra contra España, que se sitúa en el contexto de la lucha ideológica de las potencias colonialistas europeas por la prevalencia en el nuevo continente. 
¿Qué impulso los condujo

A la salvaje tierra americana?

¡Quién sabe! Acaso el mismo misterioso

Que une las notas que en el aire vagan ... (1119-22).

El adjetivo salvaje es repetido hasta la extenuación, siempre en referencia al "indio" o al suelo americano, a pesar de que en las últimas ediciones el autor usó palabras sustitutas para aliviar un poco al texto de la excesiva repetición del vocablo. El poeta se encarga de dejar bien claros los opuestos que operan tras el binomio civilización / barbarie que estructura la obra. Queda claro que de los dos salvajes elementos: indio y suelo, el primero no responde a la obra redentora. No queda, por lo tanto, otro remedio que su exterminio físico para proceder a su exaltación al plano de leyenda patria. Los charrúas terminan así como ingrediente de civismo nacional, como apropiación mítica fundamental del carácter uruguayo, definido por la "garra charrúa".

Tabaré nos presenta el caso de un héroe nacional creado a través de la literatura, como elemento integral en el proceso de construcción del discurso nacionalista y del concepto de nación, que desde finales del siglo XVIII y a lo largo del XIX se convirtió en la norma internacional de organización política. Esta entidad requería de un repositorio que orientara la ilusión de comunidad legitimada por un pasado común, con sus héroes y símbolos. Como afirma María Inés de Torres, "la tarea de edificar un estado significa tanto erigir un sistema institucional, político y económico, como acuñar un sistema verbo-simbólico que lo legitime" (118).

Zorrilla de San Martín ya había prestado su pluma a la forja de la joven nación en poemas como La leyenda patria (1879), que se leyó en la inauguración del monumento a la declaratoria de la independencia en Florida, y después del Tabaré consagraría sus dotes literarias y oratorias a esta tarea -lo que le ha ganado el epíteto de "poeta de la patria"-, con conferencias como Descubrimiento y conquista del Río de la Plata (1892), en ocasión al cuarto centenario del descubrimiento de América, y obras como La Epopeya de Artigas: Historia de los tiempos heroicos del Uruguay (1910). Pero este servicio a 
la construcción de la patria y sus héroes nacionales fue siempre de la mano con su servicio fervoroso a la iglesia católica y a la difusión de sus idearios, ${ }^{14}$ en una etapa caracterizada por un clima anticlerical que de Europa se esparció a Hispanoamérica entre una importante facción de los liberales, y que en el Uruguay constituyó, a lo largo de la segunda mitad del siglo XIX, uno de los polos en el debate sobre cuál debía ser la participación de la iglesia católica en la vida pública, cuál su relación con el Estado y cuál el límite de sus atribuciones.

El debate se extendió hasta la vuelta del siglo XX, como se aprecia en la polémica entre José Enrique Rodó y Pedro Díaz en torno a unos crucifijos que fueron retirados de los hospitales públicos (acto que el autor de Ariel calificó como jacobinista), polémica cuyos pormenores recogen Pablo Da Silveira y Susana Monreal en su libro Liberalismo y jacobinismo en el Uruguay batllista: la polémica entre José Enrique Rodó y Pedro Díaz. Estas discusiones y argumentaciones se ventilaban en los principales diarios, católicos unos, como El bien público, fundado por Zorrilla de San Martín, o de corte liberal otros, como La Antorcha, El Día y El Libre Pensamiento, entre muchos otros. Razón o fe (1900), de Mariano B. Berro, constituye un importante testimonio del combate al clericalismo, al compilar artículos publicados en El "Teléfono" de Mercedes a lo largo de la última década del siglo XIX. Por su parte, Zorrilla de San Martín se alineó con la Comisión de Señoras Católicas (las "crucíferas", para los liberales) y con su amigo y excondiscípulo, el arzobispo Mariano Soler, en todas las cruzadas para apoyar la injerencia de la Iglesia Católica en las diversas esferas de la vida pública y otras causas. En algún momento incluso el papa León XIII le otorgó la Espuela de Oro de San Silvestre, "por su profundo sentido católico" (Calderón 96).

El celo y devoción por la fe católica aparece como principio estructurante en Tabaré, en la figura de Magdalena, al principio, y en

14 “'Zorrilla llega al país en un momento polémico desde el punto de vista filosófico-religioso, y se coloca en la defensa militante del catolicismo, ya sea como orador, poeta o periodista ... Funda junto con Francisco Bauzá el 'Club Católico’, donde el catolicismo dogmático de posición ortodoxa se opone en el Ateneo al deísmo influido por las corrientes liberales" (Torres 119). 
la del Padre Esteban, al final. El poema termina con "la oración del monje por los muertos" (4738), en una imagen plástica que hace pensar en un grupo escultórico representando el motivo de "La piedad". Magdalena, por su parte, fiel al modelo de las cautivas que tienen su prototipo en Lucía Miranda, es presentada con atributos de santidad. Se presenta siempre en actitud contemplativa:

Siempre mirar al cielo [la vieron los charrúas] y más allá... miraba lo invisible, con los ojos azules y serenos (456-58)

Al cacique que está a su lado "lo domina el misterio" (460), y ella emite un blanco reflejo "de que se forma el nimbo de los mártires" (465). De sus labios el desierto en soledad escucha las plegarias y los cantos cristianos impregnados: "de inocencia y misterio, / que acaso aquella tierra escuchó un día" (500-01), que sugieren una nueva referencia a un antiguo estado de gracia y a una subsecuente "caída" del mundo americano. Todo esto refuerza la concepción teológica que explica el fondo de la obra, la caída explica la actitud de los indios, quienes vagan errantes y perdidos, animalizados, por las extensas soledades, y quienes proveen el necesario contraste a la virtud y la piedad cristiana de los españoles. El canto cinco describe el bautismo que recibe Tabaré de manos de su madre, en ese momento depositaria de la gracia redentora. "Es la hermosa mujer del Evangelio" (634), dice la voz poética, que describe en todo el canto la espiritualidad y el misterio del acto. En el siguiente canto (sexto) aparece ya el niño que hereda el fervor religioso de la madre, siempre rezando y hablando de la cruz, de ángeles y de "la virgen invisible / que me enseñas a amar..." (579). Estas escenas piadosas se alternan y contrastan con las del indio degenerado del romanticismo platense:

Las tribus embriagadas

aullaban a lo lejos;

el aire, con los roncos alaridos, elaboraba quejas y lamentos. 
Tras la salvaje orgía, vendrá el cacique ebrio; vendrá a buscar a su cautiva blanca, que a su hijo esconderá tras de los ceibos (607-14).

Son los mismos indios ebrios y orgiásticos del "festín" que trazó con mucho más detalle Esteban Echeverría en La cautiva. Es difícil ver en Tabaré una típica obra indianista cuando la participación de los indios está siempre en un registro negativo. Lo más elogioso sobre ellos es la referencia a su carácter indómito, que por supuesto va asociado a los rasgos de animalidad y salvajismo, bajo la idea de Sarmiento que citamos antes en el sentido de "animales más reacios, menos aptos para la civilización y asimilación europea”. Hay un contraste marcado entre los rasgos del jefe español -un modelo de caballerosidad y de virtud; un hombre familiar, piadoso, intachable en su conducta- y los de los caciques indios (Caracé y Yamandú): ebrios, crueles y degradados. ${ }^{15}$ Ya desde los parámetros que justifican su liderazgo recalcan la diferenciación: son los más despiadados, los que tienen más cicatrices, más cabelleras de enemigos muertos en su toldo, más mujeres. Es a partir de sus actos de rapto y violación (que queda solo en intento en el caso de Yamandú), que se complica y desarrolla la trama.

\section{Entre el indianismo y el antiindianismo}

¿En qué parte del espectro que va del indianismo al antiindianismo se encuentra Tabare? Parece, en principio, tener muchos de los ingredientes de una obra indianista: está situado en tiempos lejanos, en los inicios de la conquista, en los primeros encuentros entre las

${ }^{15}$ La construcción de oposiciones excluyentes, la justificación teológica del exterminio y la mitificación de la raza extinguida son estrategias para la fundación de lo mítico-nacional a través del cual opera el proceso de legitimación de la ideología estatal, que María Inés de Torres describe a detalle en ¿La nación tiene cara de mujer? (120-31). 
dos culturas $;{ }^{16}$ tiene por protagonista epónimo a un personaje indígena (Tabaré) y a la naturaleza americana; describe ceremonias y costumbres de una etnia americana (los charrúas).

En el otro extremo del espectro, a pesar de que nos hemos ceñido a la definición proporcionada por Concha Meléndez para la literatura, vemos que el poema nacional de Uruguay y su contexto también se adhieren a la definición del concepto de "anti-indianism" -que también toca el plano ideológico- que para el ámbito estadounidense propone la académica Elizabeth Cook-Lynn:

First and foremost, it is the sentiment that results in unnatural death to indians. Anti-Indianism is that which treats Indians and their tribes as though they don't exist ... Second, Anti-Indianism is that which denigrates, demonizes, and insult being Indian in America. The third trait of Anti-Indianism is the use of historical event and experience to place the blame on Indians for an unfortunate and dissatisfying history. And, finally, Anti-Indianism is that which exploits and distorts Indian cultures and beliefs (x).

Andrés Lamas explicaba de esta manera, en 1842, la escasez de poesía de temática indígena en Uruguay:

[E]ntre nosotros no existe esta poesía indigenista, porque no somos un pueblo original ni primitivo. La espada de la conquista aniquiló a los antiguos señores de estos países, o los encerró en el desierto con sus hábitos y recuerdos ... un abismo sin orillas separa a la raza indígena de la raza conquistadora (citado en Seluja 18).

En las palabras de Lamas se hace referencia a esos dos tipos de extinción a que se refiere el primer rasgo del antiindigenismo según lo define Cook-Lynn: la extinción en el plano de lo físico y el borramiento ideológico a que fueron sistemáticamente sometidos los pue-

${ }^{16}$ Houot sitúa la acción en las últimas décadas del siglo XVI (264). 
blos indígenas, el cual es también una forma de aniquilación. Fernando Klein da cuenta de las campañas de exterminio contra los charrúas que culminaron en el ignominioso episodio de Salsipuedes (8-10).

El segundo rasgo (denigración y demonización del indio) tendría que ver con la manera degradada en que se describe a los charrúas en el poema y que ya se ha expuesto ampliamente a lo largo del trabajo. Respecto al tercer rasgo (culpar a los indios de su propio exterminio), para María Inés de Torres, en Tabaré “el poeta, más que desentrañar el por qué de la extinción de una raza, se presenta con el poder para justificarla. Porque debajo del tono de lamento elegíaco, hay una verdadera justificación teológica de esta extinción" (125).

El último rasgo del antiindianismo (distorsionar la cultura y creencias indígenas) está ampliamente expuesto por Annie Houot. Al contrastar la imagen literaria de los charrúas, aportada por Zorrilla de San Martín, con la imagen documental recogida en testimonios de los contemporáneos de esta etnia a principios del XIX, la investigadora francesa no deja de reparar en el carácter dramatizante y ficcional de la primera, poco apegada al referente de carne y hueso: "De su vida social el autor nos da solamente tres aspectos y hemos visto que los elementos descritos, si son testificados por otras tribus amerindias, no corresponden a la realidad charrúa" (286).

Entre esas falsas atribuciones, Houot señala creencias y ritos funerarios que aportan gran dramatismo a la obra, pero que en realidad corresponden a otras tribus americanas (inspirados, sospecha Houot, en los que relata Chateaubriand en su Viaje a América). Al respecto comenta que "el resultado de esa escena es perfectamente verosímil, mucho más espectacular que la realidad charrúa que nos describen los testigos" (278).

Otro tanto se da cuando el poeta uruguayo intenta recrear la cosmovisión de los charrúas utilizando los giros lingüísticos del guaraní, lenguaje que no guarda ninguna relación con el de los primeros, o mediante el hecho de que el malón tenga lugar en la noche y no al alba como era la costumbre. Los referentes históricos quedan siempre subordinados a los efectos dramáticos y estos llegan a instalarse en la imaginación nacional con visos de autenticidad. 
Houot muestra cómo incluso intelectuales como Zum Felde caen en ese garlito de falsa "genuinidad" (286).

Respecto al canto VII en que Yamandú aparece huyendo en medio de la noche, Houot apunta: "Esa huida solitaria de Yamandú abandonando a sus compañeros en el combate, no puede de ninguna manera corresponder al comportamiento de un guerrero charrúa" y se pregunta: "¿Imaginación o intención, quizá inconsciente, en difamar al hombre-charrúa?” (Houot 275).

Borramiento, denigración, inculpación, difamación: todos los rasgos del antiindianismo propuestos por Cook-Lynn son imputables al poema nacional del Uruguay, y la pregunta de Houot nos lleva a una reflexión sobre cómo se transfiere la ideología a la obra artística. ¿Se trata de un proceso inconsciente o intencional? En su propia interpretación del poema, Houot aproxima una respuesta:

Para nosotros la muerte de Tabaré significa más el símbolo de la condena del mestizaje que el símbolo de la desaparición de la raza charrúa. En la Epopeya de Artigas, Zorrilla de San Martín afirma que las razas puras dominan y que la ley de la evolución ocasiona la desaparición de los "híbridos". Este comentario nos invita a pensar que inconscientemente el autor ya había emitido esta opinión en Tabaré ... La muerte del mestizo Tabaré prueba que no hay salvación para el mestizaje. Es afirmar indirectamente que el Uruguay y la región de la Plata que "nacieron de la sonrisa de Dios" estaban destinados para una raza pura, el Español (283-84).

Tabaré, dice Verdesio, constituye el broche de oro a la narrativa de la extinción de los charrúas, contribuyendo a que Uruguay se piense a sí mismo como "país sin indios" y a que predomine la imagen de "una sociedad conformada por gran número de ciudadanos de ascendencia europea, con valores occidentales y vocación cosmopolita" (88).

María Inés de Torres, por su parte, se pregunta:

¿Cómo construir una identidad sin un otro? . . . lo cierto es que desde su nacimiento hasta la modernización ... las repú- 
blicas nacientes pudieron, por vOz de su sector letrado, erigir un discurso en el que se plasmaban sus fantasías de ser un único sujeto blanco, masculino, europeo, culto. Por eso es que el discurso hegemónico que el sector letrado latinoamericano elabora es el de un sujeto central blanco, masculino, europeo, culto, aunque sus productores no fueran enteramente ninguna de estas cosas (70).

\section{Conclusiones}

El poema Tabaré, de Zorrilla de San Martín, considerado por algunos críticos una de las últimas y más importantes obras del indianismo hispanoamericano, ${ }^{17}$ presenta en su constitución una lógica y un desarrollo que nos obligan, al menos, a matizar la pertinencia de esta categorización. Híbrido y complejo como su personaje epónimo, Tabaré ostenta un alma hispanófila y antiindianista disimulada detrás de su apariencia indianista.

Heredero en parte de una tradición distinta a la de las zonas donde floreció el indianismo, de una tradición edificada sobre sus propios mitos etnocéntricos en los que el indio aparecía como factor de desastre, como oscura figura belicosa y ajena a toda posibilidad de civilización, y como freno del tan ansiado progreso occidental, es heredero también, por otra parte, de una literatura fundacional que buscaba constituir un repositorio de símbolos e imágenes patrios que consolidaran la idea de nación, de identidad cultural, de genealogía rastreable a un pasado lejano bien enraizado en tierras americanas como parte de una estrategia de legitimación. Esta obra resultó en la paradoja de lo que podríamos denominar, si se nos permite el oxímoron, una obra de indianismo antiindianista,

17 Thomas O. Bente la considera junto con Cumandá "cumbres del indianismo romántico hispoanoamericano". Julio Rodríguez-Luis la cita, junto con Cumandá y Enriquillo, como ejemplo de una tradición indianista estrechamente ligada con la búsqueda romántica de lo autóctono americano, que demuestra la importancia del indio como objeto cultural (8). 
que quiso armonizar la apología del exterminio con la glorificación de la "garra" ancestral del pueblo sometido. Dicha "garra" combinada con la revalorización del legado hispánico y el abrazo a la por entonces tan vilipendiada fe católica, conformarían los ingredientes aptos a una renovada identidad cívica forjada a la medida de la patria en ciernes.

\section{Bibliografía}

Anderson Imbert, Enrique. Análisis de Tabaré. Centro Editor de América Latina, 1968.

Ascasubi, Hilario. Santos Vega o los mellizos de la flor. Stockcero, 2004. Bente, Thomas O. "Cumandá y Tabaré: dos cumbres del indianismo romántico hispanoamericano". Review of Interamerican Bibliography, vol. 41, no. 1, 1991, pp. 15-23.

Calderón Quijano, José Antonio. "El IV centenario del descubrimiento en la ilustración española y americana y el Ateneo de Madrid". Andalucía y América en el siglo XIX: Actas de las V jornadas de Andalucia y América. Coordinado por Bibiano Torres Ramírez y José Hernández Palomo, Universidad de Santa María de la Rábida, pp. 15-96.

Cometta Manzoni, Aída. El indio en la poesía de América española. Joaquín Torres, 1939.

Cook-Lynn, Elizabeth. Anti-Indigenism in Modern America: A Voice from Tatekeya's Earth. U. of Illinois P., 2001.

Cornejo Polar, Antonio. La novela indigenista. Lasontay, 1980.

Da Silveira, Pablo y Susana Monreal. Liberalismo y jacobinismo en el Uruguay batllista: la polémica entre José Enrique Rodó y Pedro Diaz. Taurus, 2003.

Del Barco Centenera, Martín. La Argentina o la conquista del Río de la Plata. Theoría, 1994.

Díaz de Guzmán, Ruy. La Argentina. Espasa-Calpe, 1945.

Echeverría, Esteban. El matadero. La cautiva. Editado por Leonor Fleming, Cátedra, 1986.

Guerra, Rosa. Lucía Miranda. UBA, 1956. 
Hernández, José. Martin Fierro. Castalia, 1994.

Houot, Annie. Charrúas y Guaranies en la literatura uruguaya del siglo XIX: realidad y ficción. Linardi y Risso, 2007.

Klein, Fernando. "El destino de los indígenas del Uruguay". Nómadas: Revista Crítica de Ciencias Sociales y Jurídicas, vol. 15, no. 1, 2007, http://pendientedemigracion.ucm.es/info/nomadas/15/fernandoklein.pdf

Mansilla, Eduarda. Lucía Miranda. Edición de María Rosa Lojo, Iberoamericana, 2007.

Medina Vidal, Jorge. "El tópico de 'La Cautiva' en la literatura rioplatense". IES, vol. 2, no. 3, 1957.

Meléndez, Concha. La novela indianista en Hispanoamérica. Universidad de Puerto Rico, 1961.

Merenson, Silvina. "Cuando ser indio no rinde: sociedad política, particularismo y excepción en las narrativas nacionales del Uruguay". Espaço Ameríndio, vol 4, no. 2, 2010, pp. 172-90.

Rodríguez-Luis, Julio. Hermenéutica y praxis del indigenismo: la novela indigenista de Clorinda Matto a José María Arguedas. FCE, 1980.

Sacoto, Antonio. El indio en el ensayo de la América española. Casa de la Cultura Ecuatoriana, 1981.

Sánchez, Luis Alberto. Indianismo e indigenismo en la literatura peruana. Mosca Azul Editores, 1982.

Seluja, Antonio. Estudio preliminar. Tabaré, por José Zorrilla de San Martín. Universidad de la República, 1984, pp. 12-90.

Torres, María Inés de. ¿La nación tiene cara de mujer? Mujeres y nación en el imaginario letrado del siglo XIX. Arca, 1995.

Verdesio, Gustavo. "Un fantasma recorre el Uruguay: la reemergencia charrúa en un 'país sin indios"'. Cuadernos de literatura, vol. 18, no. 36, 2014, pp. 86-107.

Wasserman, Fabio. Entre Clío y la Polis: conocimiento histórico y representaciones del pasado en el Río de La Plata (1830-1860). Teseo, 2008.

Zorrilla de San Martín, Juan. Tabaré. Edición de Antonio Seluja. Universidad de la República, 1984.

Zum Felde, Alberto. Prólogo. Tabaré, por Juan Zorrilla de San Martín. Biblioteca Artigas, 1956. 